\title{
Carreras profesionales de clase mundial
}

\author{
World-class professional careers
}

A nivel mundial, el sector de educación cumple un rol trascendental dentro de las metas de desarrollo sostenible de los países, siendo las universidades las encargadas de lograr la formación de profesionales altamente competentes, con el propósito de brindar las soluciones adecuadas a las problemáticas de la sociedad.

Las universidades asignan responsabilidades a las carreras profesionales, quienes diseñan, ejecutan y evalúan el Plan Curricular, que incluye la justificación, los objetivos de la carrera, el perfil de ingreso, el perfil de egreso, la estructura del plan de estudio, la malla curricular, las estrategias de formación y evaluación de los aprendizajes.

Las carreras profesionales, en su camino para ser de clase mundial, se caracterizan por revisar, actualizar, evaluar y difundir permanentemente el perfil de egreso. La revisión del perfil de egreso debe contener el cumplimiento de las competencias generales y específicas tanto en el proceso formativo del estudiante como la del egresado. En esta revisión y evaluación deberán participar activamente las autoridades universitarias, docentes, estudiantes y los grupos de interés.

Asimismo, es importante el alineamiento tanto del perfil de egreso con la misión de la carrera profesional y el plan curricular como la del perfil de egreso con los sílabos (resultados de aprendizaje, contenidos, estrategias didácticas y la evaluación) con la finalidad de lograr formar profesionales que logren impacto en la sociedad tomando en cuenta las necesidades del país y del mercado laboral (empleabilidad).

En concordancia con lo anterior, el rol del docente cambia y actúa como un facilitador, guía y apoyo en la búsqueda de información relevante y coaching. El rol del estudiante debe ser como un agente activo del proceso enseñanza-aprendizaje, de búsqueda permanente de información, proactivo, innovador y juicio crítico.

Por otro lado, las carreras profesionales deben buscar estar acreditadas, contar con un plan estratégico, un enfoque de gestión de procesos, un sistema de información académico-administrativo, implementar buenas prácticas, un plan de desarrollo del docente, tutoría y consejería psicológica.

En este contexto, las carreras profesionales incorporarán transversalmente la filosofía del mejoramiento continuo a través del ciclo de planificar, hacer, verificar y actuar (PHVA) con el propósito de identificar las causas de los problemas y dar la mejor solución al respecto.

En el caso particular de la carrera profesional de la Facultad de Estomatología de la Universidad Peruana Cayetano Heredia (UPCH), se está direccionando su gestión con un enfoque de clase mundial. Éste cuenta con un 
plan curricular actualizado, un perfil de egreso, implementación del nuevo rol del docente y estudiante, acreditación, certificación de ISO 9001:2015 de los servicios odontológicos y la implementación de la filosofía de mejoramiento continuo.

Jorge Vasquez -Alva ${ }^{1, a ; ~ 2, b, c ~}$

\section{Referencias Bibliograficas}

1. Universidad Peruana Cayetano Heredia, (2016). Plan curricular de la carrera profesional de Estomatología. Lima-Perú.

2. Sistema Nacional de Evaluación, Acreditación y certificación de la calidad educativa (2016). Modelo de Acreditación para programas de estudios de educación superior universitarios. Lima-Perú

Unidad integrada de gestión de la calidad y gestión de egresados, Facultad de Estomatología Roberto Beltrán, Universidad Peruana Cayetano Heredia. Lima, Perú.

Facultad de Estomatología Roberto Beltrán, Universidad Peruana Cayetano Heredia. Lima, Perú.

Jefe Adjunto

Magister en Administración en Salud.

Profesor asociado 